\title{
Gestão Orçamentária em Empresas Familiares
}

\section{Budget Management in Family Companies}

\author{
Recebido: 02/03/2020 - Aprovado: 01/06/2020 - Publicado:01/07/2020 \\ Processo de Avaliação: Double Blind Review
}

\author{
Leonardo Fabris Lugoboni \\ leonardo.lugoboni@gmail.com \\ FECAP, Brasil \\ https://orcid.org/0000-0003-1396-9681 \\ Ana Caroline Silva Miguel \\ anacarolinesilvamiguel@gmail.com \\ Uninove Vila Prudente, Brasil \\ https://orcid.org/0000-0001-8455-4059 \\ Bruna Alves Da Silva \\ brubaamada@gmail.com \\ Anhanguera SBC, Brasil \\ https://orcid.org/0000-0002-4884-9770 \\ Geovana De Morais Oliveira \\ geovana.moraisse@gmail.com \\ FASB, Brasil \\ https://orcid.org/0000-0002-5783-0465 \\ Valmir de Santana Santos Junior \\ valmirss@hotmail.com \\ Fatec Osasco, Brasil \\ https://orcid.org/0000-0002-2297-9673
}

\section{RESUMO}

O orçamento e o planejamento são ferramentas de gestão fundamentais, atualmente, por proporcionarem uma visão ampla e atual da organização. Partindo dessa premissa, o presente artigo tem como objetivo apresentar a pesquisa compreender como é o processo de construção, execução e controle do orçamento em empresas familiares. O projeto consiste no levantamento de dados com 5 empresas familiares distribuidoras de combustíveis, onde foram realizadas as entrevistas com os gerentes financeiros. Após a coleta dos dados, observou-se que o fato dos membros da família interferirem ou se 
envolverem diretamente na construção, execução e controle do orçamento, pode atrapalhar o processo por meio de divergências de ideias entre os familiares, o que dificulta alguns procedimentos que poderiam ser resolvidos em dias, mas levam semanas para serem concluídos. Por outro lado, percebeu-se, também, que os processos ocorrem com mais agilidade, o que é um grande diferencial. Além disso, quando o profissionalismo dos familiares é bem estruturado, a empresa ganha um grande diferencial, gerando harmonia entre funcionários e diretores, o que aumenta a competitividade e rapidez.

Palavras-chave: empresas familiares, orçamento, planejamento.

\begin{abstract}
Budgeting and planning are essential management tools nowadays, as they provide a whole and current view of the organization. Based on this premise, this article aims to present a research about the process of construction, execution and budget control in family businesses. The project consists of collecting data with five family companies of fuel distributors, whose interviews were conducted with financial managers. After data collection, it was shown the fact that family members interfere or get directly involved in the construction, execution and budget control, it might also disturb the process through divergences of ideas among family members, even if they hardly put into practice methods that could be solved in days, but it takes weeks to be fulfilled. On the other hand, we also realize that the processes occur more quickly, which is observed that is huge difference. Moreover, when the family professionalism is well-structured, a company acquires a deal of widening gap, in addition to generating harmony among employees and directors, resulting in high amount of competitiveness and agility.
\end{abstract}

Keywords: family businesses, budget, planning.

\title{
1. INTRODUÇÃO
}

Orçamento é uma das principais ferramentas de gestão utilizado para diferentes objetivos segundo Mucci, Frezatti, Dieng (2016).

REMIPE- Revista de Micro e Pequenas Empresas e Empreendedorismo da Fatec Osasco 
As técnicas de orçamento devem ser constantemente melhoradas e adaptadas à realidade das organizações. A fixação da técnica está na ausência de um modelo pronto e ajustável para cada empresa, assim, a evolução constante deve ser incentivada, tanto da técnica como da educação orçamentária organizacional (FERREIRA; DIEHL, 2012).

Pode ser definido como um plano que estabelece necessidades de investimentos e financiamentos para uma perspectiva projetada da empresa. $\mathrm{O}$ orçamento oferece sustentabilidade às organizações diante da concorrência, abertura de mercados e necessidade constante de alteração aos fatores mercadológicos (LIMA FILHO; BRUNI, 2013).

De acordo com Beck, Cunha e Franz (2015), muitas empresas são administradas por seus fundadores, por suas famílias ou herdeiros, denominando-se assim, empresas familiares. Para essas empresas, a sucessão empresarial é fundamental, pois muitas se deixam consumir em virtude dos problemas sucessórios na rota entre a primeira e a terceira geração (COSTA et al., 2015).

Afirmam Lescura, Borges e Brito (2012) que as organizações direcionadas por indivíduos de uma família, apresentam características que instigam os pesquisadores, pois tornam sua gestão diferenciada dos demais empreendimentos.

Esta pesquisa tem como objetivo compreender como é o processo de construção, execução e controle do orçamento em empresas familiares e se justifica pois o planejamento, assim como o orçamento, são ferramentas de gestão que permitem uma visão futura da empresa, portanto, necessários para a tomada de decisão, evitando o mau uso dos recursos, resultando na otimização dos resultados (SOUZA; CANTON; JOHANN, 2014).

De acordo com Mucci, Frezzati e Dieng (2016), empresas familiares e de pequeno porte têm problemas com a gestão dos recursos, tanto por vincular o patrimônio da empresa com o familiar e vice-versa, quanto pela dinâmica organizacional sustentada pela informalidade e o desconhecimento do negócio. 


\section{REFERENCIAL TEORICO}

\subsection{Orçamento}

O orçamento é uma composição de fluxo de informação, processos e procedimentos administrativos, sendo parte adicional do planejamento de curto prazo e do sistema de controle de uma organização, afirmam Gomes, Lavarda e Torrens (2011).

É um instrumento de gestão, portanto, sua utilização poderia contribuir para um melhor sistema de controle, permitindo as empresas uma melhor avaliação sobre as estratégias do negócio, contribuindo na tomada de decisão (MARTH; FEIL, 2014). Os orçamentos podem ser efetuados como parte de um sistema de gestão tanto para um controle financeiro, como para as metas estabelecidas, permitindo aos gestores rápidas respostas em frente a situações imprevistas (ZAMBON; FASSINA, 2014).

Nesse contexto, o orçamento é classificado como um plano financeiro de uma instituição. A administração de qualquer organização pública ou privada, com ou sem fins lucrativos, deve estabelecer objetivos e criar metas, expondo em um plano financeiro, em moeda atual, para que possam ser acompanhadas e avaliadas pelos gestores da organização, certificam Quintana, Perazo e Fernandes (2013).

Souza, Canton e Johann (2014) esclarecem a importância do orçamento nas projeções do planejamento estratégico, visto que as constantes mudanças que vêm ocorrendo no ambiente dos negócios acabam por induzir as empresas a aprimorarem seus processos de planejamento, avaliação e controle, tanto do seu fluxo de caixa, quanto das operações de receitas, despesas e investimentos.

Dessa maneira, Priore et al. (2015) esclarecem que por meio do orçamento é possível visualizar e verificar o crescimento da organização, padronizando objetivos e metas de forma clara e transparente, facilitando ao gestor uma rápida análise das situações diárias e constantes.

A importância do orçamento também é entendida por outros autores como a estima das metas do planejamento estratégico e o desmembramento das instruções e políticas estratégicas dele definidas (FERREIRA; DIEHL, 2012).

Com base nisso, Lima Filho e Bruni (2013) afirmam que o orçamento pode ser definido como um plano que estabelece limites de investimentos e financiamentos para 
um cenário projetado da empresa. Logo, o orçamento oferece sustentabilidade às organizações diante da rivalidade, abertura de mercados e necessidade constante de transformação aos fatores mercadológicos.

Os objetivos do orçamento devem estar alinhados com os definidos no planejamento estratégico e tático. Bem como relacionados ao ciclo administrativo: planejamento, execução e controle. No planejamento, o orçamento pode materializar os objetivos sob a forma de valor. Na execução, contribui para orientar as ações e decisões, assegurando a eficácia da organização e o controle que possibilita a difusão dos planos e contribuindo na avaliação de desempenho, comparando suas medidas com o realizado. Assim, fornecendo os critérios para avaliar o resultado global da organização e o desempenho dos diferentes centros de responsabilidade por meio da análise e identificação dos desvios e, em caso de necessidade, a elaboração dos modelos de adequação (LUNKES; FELIU; ROSA, 2011).

Atualmente, o orçamento nas empresas pode se desenvolver de forma mais segura por meio do acompanhamento da execução das atividades, alargando o mercado e conquistando novos clientes, influenciando, dessa forma, o desenvolvimento econômico e social do estado ou município no qual estejam inseridas, gerando emprego e renda para a população (CHAGAS; ARAÚJO, 2013).

Foi consolidado por Ferreira e Diehl (2012) no Quadro 1, ideias sobre a evolução e elaboração de um orçamento empresarial, utilizando desenvolvimento teórico de diversos modelos, do mesmo: 


\section{QUADRO 1: Teoria de modelos de orçamento}

\begin{tabular}{|c|l|}
\hline Modelo & \multicolumn{1}{|c|}{ Descrição } \\
\hline $\begin{array}{c}\text { Estático ou Perpetuo } \\
\text { (NASCIMENTO e } \\
\text { REGINATO, 2009) }\end{array}$ & $\begin{array}{l}\text { Projeção das expectativas de receitas, custos, despesas, investimentos e } \\
\text { demais componentes. Manutenção pelo período originalmente orçado. } \\
\text { Contém as metas associadas ao planejamento estratégico da empresa. } \\
\text { Estimula a gerência a buscar essas metas e trabalhar na melhoria. }\end{array}$ \\
\hline $\begin{array}{c}\text { Flexível } \\
\text { (HORNGREN, FOSTER e } \\
\text { DATAR, 1997) }\end{array}$ & $\begin{array}{l}\text { É um conjunto de metas em que é possível a realização de ajustes conforme } \\
\text { o nível de atividades ou receitas e medidas de custos reais. }\end{array}$ \\
\hline $\begin{array}{c}\text { Contínuo ou Rolling } \\
\text { (LUNKES, 2003) }\end{array}$ & $\begin{array}{l}\text { Atualização contínua do orçamento operacional. Acrescenta } \\
\text { no fim de cada ciclo um novo período, sendo esta variável. }\end{array}$ \\
\hline $\begin{array}{c}\text { Ajustado (Forecast) } \\
\text { (PADOVEZE e TARANTO, } \\
\text { 2009) }\end{array}$ & $\begin{array}{l}\text { Mais flexível, pois permite ajustes no orçamento original conforme ocorram } \\
\text { mudanças significativas nos rumos das operações ou da gestão (visão interna) } \\
\text { ou do mercado (visão externa). }\end{array}$ \\
\hline $\begin{array}{c}\text { Orçamento Base Zero } \\
\text { (NASCIMENTO e }\end{array}$ & $\begin{array}{l}\text { Na etapa de planejamento do orçamento, torna-se como ponto de partida um } \\
\text { saldo zero e para qualquer valor incluído há necessidades de justificativas. } \\
\text { Descarta orçamentos históricos. }\end{array}$ \\
\hline $\begin{array}{c}\text { Orçamento por Atividades } \\
\text { (LUNKES, 2009) }\end{array}$ & $\begin{array}{l}\text { Focaliza as atividades e os recursos para atingir as metas estabelecidas. É } \\
\text { baseado nos conceitos fundamentais do método de custeio ABC. }\end{array}$ \\
\hline
\end{tabular}

Fonte: Ferreira e Diehl (2012)

\subsection{Modelo e Elaboração do Orçamento}

A utilização de ferramentas sofisticadas auxilia na gestão das empresas, relacionadas aos custos de produção, pois cria um diferencial competitivo entre empresas concorrentes. Tais ferramentas proporcionam informações sobre o processo produtivo, facilitando a tomada de decisão quanto à redução de custos sem comprometer a qualidade de seus bens e serviços e agregando maiores vantagens competitivas (SILVA; ROSA; PIRES, 2007).

Uma das técnicas de planejamento financeiro utilizada pelas organizações é a elaboração e a implementação do planejamento e do controle de resultados, definidos por muitos autores como a elaboração e a implementação do orçamento (COSTA; MOORITZ;MACHADO, 2007).

Para Leite et al. (2008), as técnicas orçamentárias podem ser executadas em qualquer economia, para qualquer entidade, bastando apenas o conhecimento dos efeitos decorrentes da inflação. Deve-se entender que os fatores externos, como tendências de mercados, condições econômicas e outras variáveis ambientais devem ser consideradas no processo de elaboração do orçamento (ALMEIDA et al., 2009).

A partir dessas informações, foram selecionados três modelos de orçamento por periodicidade de utilização nas entidades, sendo esses: Orçamento Matricial, Orçamento Base Zero e Orçamento por Atividades. 


\subsection{Orçamento em Empresas Familiares}

Uma empresa é tida como familiar ao se notar a família comandando ou praticando grande influência sobre os assuntos sociais e gerenciais. Esses tipos de empresas possuem muitas particularidades que as colocam em vantagens e desvantagens em relação às outras organizações (ALVES; BUSS, 2009).

A mesma não representa um grupo homogêneo, mas há diversos fatores que a diferencia, como do grau de envolvimento da família a presença de membros que não são da família, tanto na propriedade, bem como na governança e na gestão, e isso também caracteriza a empresa nas questões de contabilidade (SONGINI; GNAN; MALMI, 2013).

Como pontos de desvantagens das empresas familiares, viram-se aspectos ligados à sua estrutura organizacional informal, gestão desorganizada, confusão entre família e empresa e camuflagem de problemas. Já como pontos que lhe trazem vantagens, apontaram-se: a agilidade na tomada de decisões; os colaboradores, que ficam unidos pelo encanto que sentem em relação ao fundador; a família, que busca conhecer a fundo o negócio; os clientes, que sentem mais confiança, entre outros, declaram os autores Alves e Buss (2009).

As empresas familiares são caracterizadas pela necessidade de equilibrar as identidades divergentes, interesses e prioridades dos membros da família e dos sistemas de negócios, dos quais os aspectos citados são particularmente difíceis para se capturar através de métodos quantitativos (MASSIS; KOTLAR, 2014).

De acordo com Ward (2003), existem diversas ferramentas que previnem o declínio de uma entidade. Uma dessas ferramentas é o orçamento, fundamental para orientar a empresa e a família. Se, por um lado, ele ajuda o proprietário a concentrar sua atenção no negócio por outro, garante que todos os membros da família reconheçam e enfrentem as demandas da empresa, bem como colocam em evidência as necessidades da família, abrindo as portas para que sejam levadas em conta as metas familiares.

Os autores Craig e Moores (2010) relatam que o Balanced Scorecard é um negócio da família O'Reilly e tem sido benéfico para as diversas partes interessadas, ou seja, família, diretores e gerentes. O BSC tem permitido a empresa familiar ter a certeza de que as suas expectativas têm sido instaladas como uma consideração central no desenvolvimento das estratégias de negócios e planos. 
As empresas familiares superam em muito as corporações de grande porte. Esse resultado é válido para as empresas controladas pelo fundador, gerido profissionalmente empresas familiares, mas também, para empresas dirigidas por descendentes do fundador (SRAER; THESMAR, 2007), Allouche et al. (2008) acrescentam que o nível de controle familiar influencia fortemente o desempenho, pelo menos, em termos de rentabilidade (embora os resultados não sejam tão claros para as estruturas financeiras), além disso, o nível de controle da família tem consequências para o desempenho; requer confirmação em outros contextos nacionais e institucionais.

\subsection{Estudos Correlatos}

A seguir, apresentam-se alguns estudos relevantes sobre a temática:

Priore et al. (2015), com a finalidade de apresentar a importância de utilizar os conhecimentos de planejamento e orçamento em qualquer entidade ou instituição, independente do objetivo a ser atingido, obtiveram seus resultados através de um estudo de caso de um condomínio considerado falido. Para isso, foram feitas algumas análises financeiras, análises de despesas e de controle. Diante de toda técnica estudada, concluíram que o planejamento e orçamento evita prejuízos à organização, cria bases para a tomada de decisão com alto percentual de assertividade e maior controle orçamentário, auxiliando o alcance das metas estabelecidas e de seus resultados.

Codesso, Lunkes e Suave (2013) fornecem evidências sobre as práticas orçamentárias em empresas hoteleiras na cidade de Balneário Camboriú (SC). Foi realizada uma pesquisa empírica com o envio de questionário a todos os hotéis associados à Associação da Indústria Hoteleira de Santa Catarina (ABIH-SC), com população inicial formada por 17 hotéis do Balneário Camboriú. Dessa população, 11 hotéis com orçamento formal foram selecionados com o retorno de 6 questionários. Concluindo que o objetivo desse artigo foi alcançado, pois a aplicação dos questionários permitiu explorar as práticas orçamentárias nas empresas hoteleiras, caracterizar os hotéis e observar o planejamento, a execução e o controle do orçamento.

Pontes (2013) aborda o orçamento empresarial em pequenas empresas, propondo analisar o processo financeiro de vendas e produção de uma empresa do ramo de prémoldados. Proporcionando as informações necessárias para seu orçamento empresarial, foi aplicado entrevista com os sócios-proprietários, observando as atividades 
administrativo-financeiras, comerciais e de produção, análise do livro caixa, notas fiscais, recibos e as planilhas eletrônicas utilizadas no controle interno do contas a pagar e a receber. Os resultados dessa pesquisa mostraram que a utilização do orçamento empresarial contribui para a melhoria da gestão ao permitir o desenvolvimento de ações de melhorias, como a segregação do patrimônio, a revisão de seu sistema de custeio e projeção e preço de venda e produção, corroborando com a competitividade dos negócios.

Nascimento e Teixeira (2015) avaliaram o orçamento empresarial como ferramenta de gestão e instrumento de controle na Empresa ABCIND, adquirindo suas informações através de pesquisa exploratória de abordagem qualitativa. Baseando-se nos resultados da pesquisa, essa ferramenta permite ter uma visão ampla de todo o processo e controle dos custos da organização.

Almeida et al. (2009) verificaram as relações entre o porte da cooperativa e a utilização do orçamento como ferramenta de apoio à formulação e implementação de estratégias, bem como a interatividade no processo orçamentário e a prática de controle orçamentário. Metodologicamente, é uma pesquisa exploratória e descritiva, os dados foram coletados por meio de questionários e tratados estatisticamente. Os resultados sugerem uma relação significativa entre o porte da cooperativa e a utilização do orçamento como ferramenta de apoio a estratégia e controle, quanto à interatividade, os testes indicam não haver relação significativa.

Tappeiner et al. (2012) averiguaram o controle de finanças em vinte e uma empresas familiares onde o contexto é estender a compreensão conceitual de private equity, para essa finalidade foi utilizado um estudo de caso qualitativo, que permitiu analisar as questões sensíveis ao contexto. Concluindo-se que as teorias em combinação com as experiências destacam o entrelaçamento da família e influências de negócios na demanda por capital privado. Há casos em que o financiamento foi procurado por uma combinação de razões, destacando a interdependência da procura e da oferta nas decisões de financiamento.

Craig e Moores (2010) abordam o alinhamento das questões que influenciam a família, negócios e sistemas, tendo em consideração Balanced Scorecard. A metodologia adotada é uma forma de pesquisa-ação. Determinou-se que a introdução da estrutura do 
Balanced Scorecard para os negócios tem gerado um benefício para as famílias, diretores e gerentes, garantindo o reconhecimento das visões de ambas as partes.

No Quadro 2, apresentam-se estudos recentes sobre o tema da gestão orçamentaria e empresas familiares:

\section{QUADRO 2: Estudos recentes sobre a temática}

\begin{tabular}{|c|c|c|c|}
\hline Ano & Autores & $\begin{array}{c}\text { Título } \\
\end{array}$ & $\begin{array}{l}\text { Objetivo } \\
\end{array}$ \\
\hline 2020 & $\begin{array}{l}\text { Claudia Delfin Ruiz; } \\
\text { Rodrigo Cano Gusmán; } \\
\text { Erwin José Peña } \\
\text { Valencia }\end{array}$ & $\begin{array}{l}\text { Funcionalidad familiar } \\
\text { como estrategia para la } \\
\text { generación del } \\
\text { emprendimiento social } \\
\text { en México }\end{array}$ & $\begin{array}{l}\text { Identificar as ações que permitem ter papéis definidos e } \\
\text { funcionais na família que possam promover o } \\
\text { empreendedorismo social é o objetivo central do } \\
\text { trabalho. }\end{array}$ \\
\hline 2019 & $\begin{array}{l}\text { Ana Costa de Mavárez; } \\
\text { Claudia A Molina } \\
\text { Quiroz; Tanya S } \\
\text { Andiano Chancay } \\
\text { Virginia E. Rodríguez } \\
\text { López }\end{array}$ & $\begin{array}{l}\text { Sistema familiar y } \\
\text { continuidad de las } \\
\text { empresas familiares }\end{array}$ & $\begin{array}{l}\text { Esta pesquisa tem como objetivo analisar elementos do } \\
\text { sistema familiar que podem afetar a continuidade dos } \\
\text { negócios familiares. }\end{array}$ \\
\hline 2019 & $\begin{array}{l}\text { Vinicius Costa da Silva } \\
\text { Zonatto; } \\
\text { Aline Weber; } \\
\text { Juliana Constância } \\
\text { Nascimento }\end{array}$ & $\begin{array}{l}\text { Efeitos da Participação } \\
\text { Orçamentária na } \\
\text { Assimetria } \\
\text { Informacional, Estresse } \\
\text { Ocupacional e } \\
\text { Desempenho Gerencial }\end{array}$ & $\begin{array}{l}\text { A pesquisa investiga os efeitos da participação } \\
\text { orçamentária na assimetria de informação, no estresse } \\
\text { ocupacional e no desempenho gerencial junto a } 121 \\
\text { gestores com responsabilidade orçamentária em } \\
\text { organizações industriais brasileiras. }\end{array}$ \\
\hline 2019 & $\begin{array}{l}\text { José António Porfírio } \\
\text { José Augusto Felício } \\
\text { Tiago Carrilho }\end{array}$ & $\begin{array}{l}\text { Family business } \\
\text { succession: Analysis of } \\
\text { the drivers of success } \\
\text { based on } \\
\text { entrepreneurship theory }\end{array}$ & $\begin{array}{l}\text { Este estudo explora a sucessão de empresas } \\
\text { familiares. Neste estudo, a sucessão é comparada ao } \\
\text { conceito de oportunidade versus empreendedorismo } \\
\text { necessário. As motivações dos sucessores quando } \\
\text { entram no processo de sucessão são examinadas para } \\
\text { identificar diferentes condições para o sucesso e a } \\
\text { sustentabilidade dos negócios da família. }\end{array}$ \\
\hline 2018 & $\begin{array}{l}\text { Lilian Paula Andrade } \\
\text { Monica Carvalho Alves } \\
\text { Capelle } \\
\text { Rafaella Cristina } \\
\text { Campos } \\
\text { Mozar José de Brito }\end{array}$ & $\begin{array}{l}\text { Meu pai ainda está aqui, } \\
\text { nas pessoas": sentidos } \\
\text { subjetivos nas relações } \\
\text { de trabalho em uma } \\
\text { empresa familiar }\end{array}$ & $\begin{array}{l}\text { Este estudo tem como objetivo compreender os } \\
\text { sentidos subjetivos relacionados ao trabalho na } \\
\text { perspectiva dos trabalhadores de uma empresa familiar. } \\
\text { A pesquisa realizada contribui para o entendimento dos } \\
\text { pressupostos teóricos dos sentidos subjetivos no } \\
\text { trabalho e ajuda na compreensão da lógica de gestão } \\
\text { em empresas familiares. }\end{array}$ \\
\hline 2017 & $\begin{array}{l}\text { Fabio Frezzati; } \\
\text { Diogenes de Souza } \\
\text { Bido; } \\
\text { Daniel Magalhães } \\
\text { Mucci; } \\
\text { Francieli Beck }\end{array}$ & $\begin{array}{l}\text { Estágio do ciclo de vida } \\
\text { e perfil de empresas } \\
\text { familiares brasileiras }\end{array}$ & $\begin{array}{l}\text { Esta pesquisa analisa a relação entre os estágios do } \\
\text { ciclo de vida organizacional (Lester, Parnell, Carraher, } \\
\& \text { Pamell, 2003) e os elementos de influência da } \\
\text { família na empresa no modelo F-PEC (Poder, } \\
\text { Experiencia e Cultura). artigo exploratório, contribui } \\
\text { para o entendimento das organizações, proporcionando } \\
\text { indicações para o desenvolvimento de análises } \\
\text { comparativas e a atuação sobre as variáveis que } \\
\text { proporcionam o planejamento de migração para } \\
\text { estágios mais desejáveis, como crescimento, } \\
\text { maturidade e rejuvenescimento. }\end{array}$ \\
\hline
\end{tabular}

Fonte: Elaborado pelos autores.

REMIPE- Revista de Micro e Pequenas Empresas e Empreendedorismo da Fatec Osasco

V. $6 \mathrm{~N}^{\circ} 2$ jul.-dez. 2020. 


\section{METODOLOGIA}

Esta pesquisa classifica-se como exploratória, pois tem como objetivo proporcionar maior conhecimento sobre o problema, podendo construir hipóteses ao final da pesquisa.

Nesse contexto, os autores Piovesan e Temporini (1995) definem a pesquisa exploratória como estudo preliminar realizado com a finalidade de melhor adequar o instrumento de medida à realidade que se pretende conhecer.

Será realizado um levantamento destinado a compreender como é o processo de construção, execução e controle do orçamento em empresas familiares do ramo de distribuição de combustíveis.

As pesquisas de levantamento de campo (survey) caracterizam-se pela interrogação direta das pessoas cujo comportamento deseja-se conhecer. Basicamente, acontece a solicitação de informações a um grupo significativo de pessoas em relação ao problema estudado para em seguida, diante da análise quantitativa, alcançar as conclusões correspondentes dos dados coletados (GIL, 1985).

A amostra é composta de 5 empresas que contém as características descritas no Quadro 3:

QUADRO 3: Amostra

\begin{tabular}{|c|c|c|c|c|c|}
\hline EMPRESA & $\mathbf{A}$ & B & $\mathbf{C}$ & D & $\mathbf{E}$ \\
\hline LOCAL & Diadema & Diadema & São Paulo & São Paulo & Diadema \\
\hline $\begin{array}{l}\text { QUANTIDADE DE } \\
\text { FUNCIONÁRIOS }\end{array}$ & 12 & 17 & 10 & 14 & 15 \\
\hline $\begin{array}{c}\text { CARGO DO } \\
\text { ENTREVISTADO }\end{array}$ & $\begin{array}{c}\text { Gerente } \\
\text { Financeiro }\end{array}$ & $\begin{array}{c}\text { Gerente } \\
\text { Financeiro }\end{array}$ & $\begin{array}{c}\text { Gerente } \\
\text { Financeiro }\end{array}$ & $\begin{array}{c}\text { Gerente } \\
\text { Financeiro }\end{array}$ & $\begin{array}{l}\text { Gerente } \\
\text { Financeiro }\end{array}$ \\
\hline $\begin{array}{c}\text { TEMPO DE } \\
\text { EMPRESA DO } \\
\text { FUNCIONÁRIO } \\
\text { (ANOS) }\end{array}$ & 17 & 22 & 15 & 21 & 16 \\
\hline $\begin{array}{c}\text { TEMPO DA } \\
\text { EMPRESA NO } \\
\text { MERCADO } \\
(\text { ANOS })\end{array}$ & 50 & 40 & 40 & 45 & 42 \\
\hline RAMO & $\begin{array}{c}\text { Distribuidora } \\
\text { de } \\
\text { Combustível } \\
\end{array}$ & $\begin{array}{l}\text { Distribuidora } \\
\text { de } \\
\text { Combustível } \\
\end{array}$ & $\begin{array}{c}\text { Distribuidora } \\
\text { de } \\
\text { Combustível } \\
\end{array}$ & $\begin{array}{c}\text { Distribuidora } \\
\text { de } \\
\text { Combustível } \\
\end{array}$ & $\begin{array}{l}\text { Distribuidora } \\
\text { de } \\
\text { Combustível } \\
\end{array}$ \\
\hline DATA & $13 / 03 / 2017$ & $03 / 04 / 2017$ & $06 / 04 / 2017$ & $19 / 04 / 2017$ & $25 / 04 / 2017$ \\
\hline
\end{tabular}

Fonte: Elaborado pelos autores

REMIPE- Revista de Micro e Pequenas Empresas e Empreendedorismo da Fatec Osasco 
QUADRO 4: Consolidação do referencial teórico

\begin{tabular}{|c|c|c|c|}
\hline ASSUNTO & TEMA & AUTOR & PERGUNTA \\
\hline \multirow{14}{*}{ ORÇAMENTO } & $\begin{array}{l}\text { Principal } \\
\text { ferramenta de } \\
\text { gestão }\end{array}$ & $\begin{array}{l}\text { Mucci, Frezzati e Dieng } \\
\qquad(2016)\end{array}$ & O orçamento é utilizado como ferramenta de gestão? \\
\hline & $\begin{array}{l}\text { Técnicas de } \\
\text { orçamento }\end{array}$ & $\begin{array}{l}\text { Ferreira e Dihel } \\
(2012)\end{array}$ & $\begin{array}{l}\text { Com qual frequência a empresa analisa seu orçamento para } \\
\text { saber se ele ainda está adequado ao exercício vigente? }\end{array}$ \\
\hline & $\begin{array}{l}\text { Plano de } \\
\text { negócios }\end{array}$ & $\begin{array}{l}\text { Lima Filho e Bruni } \\
\text { (2013) }\end{array}$ & $\begin{array}{l}\text { A empresa elabora um plano de negócios formal? O } \\
\text { orçamento está alinhado ao plano de negócios da empresa? }\end{array}$ \\
\hline & Metas & Werolin $\quad(1964)$ & Existem metas orçamentarias a serem atingidas diariamente? \\
\hline & $\begin{array}{l}\text { Modelo } \\
\text { específico }\end{array}$ & Ferreira e Dihel (2012) & $\begin{array}{c}\text { Qual modelo de orçamento é utilizado nesta empresa } \\
\text { (orçamento matricial, orçamento base zero, orçamento por } \\
\text { atividades etc.)? }\end{array}$ \\
\hline & $\begin{array}{c}\text { Plano } \\
\text { financeiro }\end{array}$ & $\begin{array}{l}\text { Quintana, Perazo e } \\
\text { Fernandes }\end{array}$ & O plano financeiro é acompanho e avaliado com frequência? \\
\hline & Crescimento & Priore et al. $\quad(2015)$ & O crescimento da organização está claro no orçamento? \\
\hline & $\begin{array}{c}\text { Planejamento } \\
\text { e orçamento }\end{array}$ & $\begin{array}{l}\text { Souza, Canton e Johann } \\
(2014)\end{array}$ & $\begin{array}{l}\text { Na hora da tomada de decisão o planejamento e orçamento } \\
\text { possuem qual prioridade? }\end{array}$ \\
\hline & Efetuado & Zambon e Fassina (2014) & $\begin{array}{l}\text { O orçamento na sua organização está mais ligado ao controle } \\
\text { financeiro ou estabelecimento de metas? }\end{array}$ \\
\hline & $\begin{array}{c}\text { Questão } \\
\text { competitiva }\end{array}$ & $\begin{array}{l}\text { Silva, Rosa e Pires } \\
\text { (2007) }\end{array}$ & Fazer um orçamento afeta sua competitividade no mercado? \\
\hline & $\begin{array}{l}\text { Fatores } \\
\text { externos }\end{array}$ & $\begin{array}{l}\text { Alemida et al. } \\
\qquad(2009)\end{array}$ & $\begin{array}{c}\text { Quais fatores externos influenciam na elaboração do } \\
\text { orçamento? Quais fatores internos influenciam na elaboração } \\
\text { do orçamento? }\end{array}$ \\
\hline & Aplicação & $\begin{array}{l}\text { Marques et al. } \\
\text { (2015) }\end{array}$ & $\begin{array}{l}\text { Quão difícil é controlar a execução do orçamento? Quais são } \\
\text { as principais dificuldades? }\end{array}$ \\
\hline & Declínio & $\begin{array}{c}\text { Ward } \\
(2003) \\
\end{array}$ & $\begin{array}{l}\text { Há ou houve previsão de prejuízos no orçamento? Por quais } \\
\text { motivos? }\end{array}$ \\
\hline & $\begin{array}{l}\text { Importância } \\
\text { das } \\
\text { ferramentas }\end{array}$ & $\begin{array}{l}\text { Priore et al. } \\
\quad(2015)\end{array}$ & $\begin{array}{l}\text { O fato de ser uma empresa familiar interfere na utilização de } \\
\text { ferramentas como orçamento e planejamento? }\end{array}$ \\
\hline \multirow{6}{*}{$\begin{array}{l}\text { EMPRESAS } \\
\text { FAMILIARES }\end{array}$} & Administração & $\begin{array}{l}\text { Beck, Cunha e Franz } \\
\text { (2015) }\end{array}$ & $\begin{array}{l}\text { A gestão desta empresa permanece com os mesmos valores e } \\
\text { processos definidos pelo fundador? O fundador está } \\
\text { preocupado com orçamento? }\end{array}$ \\
\hline & Longa data & Marques et al. (2015) & $\begin{array}{c}\text { Quantos anos a empresa está no mercado? Quantas gerações } \\
\text { da família passaram pela empresa? Sempre utilizaram } \\
\text { orçamento? }\end{array}$ \\
\hline & Rivalidade & $\begin{array}{l}\text { Lima Filho e Bruni } \\
\text { (2013) }\end{array}$ & $\begin{array}{l}\text { Ser familiar torna a empresa mais ou menos competitiva? } \\
\text { Como isso afeta o orçamento? }\end{array}$ \\
\hline & Mesclar & Marques et al. & $\begin{array}{l}\text { Por ser uma empresa familiar, há momentos em que os } \\
\text { problemas pessoais e profissionais acabam se encontrando? }\end{array}$ \\
\hline & $\begin{array}{l}\text { Membros da } \\
\text { Família }\end{array}$ & $\begin{array}{l}\text { Ward } \\
(2003)\end{array}$ & $\begin{array}{l}\text { Quais são os cargos ocupados por membros da família? Quais } \\
\text { pessoas da família se envolvem com o orçamento? }\end{array}$ \\
\hline & $\begin{array}{l}\text { Tomada de } \\
\text { decisões }\end{array}$ & Alves e Buss & $\begin{array}{c}\text { O envolvimento da família em tomadas de decisões já causou } \\
\text { problemas? Houve algum caso em que ocasionou o não } \\
\text { cumprimento do orçamento? }\end{array}$ \\
\hline \multirow{4}{*}{$\begin{array}{l}\text { ORÇAMENTO } \\
\text { EM } \\
\text { EMPRESAS } \\
\text { FAMILIARES }\end{array}$} & $\begin{array}{c}\text { Gestão } \\
\text { diferenciada }\end{array}$ & $\begin{array}{c}\text { Lescura, Borges e Brito } \\
(2012)\end{array}$ & O fato de ser familiar dificulta a tomada de decisão? \\
\hline & $\begin{array}{l}\text { Plano } \\
\text { financeiro }\end{array}$ & $\begin{array}{l}\text { Quintana, Perazo e } \\
\text { Fernandes } \\
(2013)\end{array}$ & $\begin{array}{l}\text { O fluxo financeiro da empresa é controlado por um membro } \\
\text { da família? }\end{array}$ \\
\hline & Orçamento & $\begin{array}{c}\text { Ferreira e Dihel } \\
(2012)\end{array}$ & Qual é a importância do orçamento para empresas familiares? \\
\hline & $\begin{array}{l}\text { Gestão de } \\
\text { recursos }\end{array}$ & $\begin{array}{l}\text { Mucci, Frezzati e Dieng } \\
\text { (2016) }\end{array}$ & A comunicação entre a família afeta a gestão dos recursos? \\
\hline
\end{tabular}

Fonte: Elaborado pelos autores

REMIPE- Revista de Micro e Pequenas Empresas e Empreendedorismo da Fatec Osasco

V. $6 \mathrm{~N}^{\circ} 2$ jul.-dez. 2020. 
O instrumento de pesquisa contém vinte e quatro questões, que foram baseadas na literatura do referencial.

O estudo se iniciou com a solicitação dos nomes e telefones dos gerentes financeiros por e-mail. Com o retorno, as entrevistas foram agendadas por telefone.

As entrevistas foram digitalizadas e transcritas. Após isso, foi realizado uma análise de conteúdo usando grade mista. De acordo com Vergara (2012), definem-se preliminarmente as categorias pertinentes ao objetivo da pesquisa, porém admite-se a inclusão de categorias surgidas durante o processo de análise. Verifica-se a necessidade de subdivisão, inclusão e exclusão de categorias. Estabelece-se o conjunto final de categorias, considerando o possível rearranjo.

\section{RESULTADOS E DISCUSSÃO}

Este capítulo apresenta uma exibição precisa sobre empresas familiares distribuidoras de combustíveis, localizadas no estado de São Paulo.

Quando questionados sobre utilizar a função do orçamento, todas as empresas afirmaram que utilizam como ferramenta de gestão.

A resposta dos entrevistados entra em acordo com o que foi afirmado por Marth e Feil (2014), que é considerado um instrumento de gestão que pode atender a tais necessidades e, portanto, sua utilização poderia contribuir para a composição de um melhor sistema de controle, que, por consequência, pode permitir as empresas uma melhor avaliação sobre as estratégias do negócio e contribuir na tomada de decisão:

É uma ferramenta que facilita e organiza os objetivos a serem alcançados. (Empresa B)

Ao serem questionados sobre a frequência com que analisam o orçamento, as empresas A e B declaram mensalmente para terem resultado nítidos. Já as empresas C e D dizem analisar anualmente e a empresa E analisa semestralmente.

As respostas ratificam o que foi exposto por Souza e Lunkes (2015), quando afirmaram que o orçamento pode solicitar revisões ao longo do período devido às modificações nas circunstâncias econômicas: 
O orçamento é analisado mensalmente para obtermos maior exatidão, assim não corremos riscos de falhas graves (Empresa A).

Quando questionados sobre a elaboração de um plano de negócios formal e seu alinhamento junto a empresa, somente a empresa D declarou não ter algo formal, mas ter em mente essa lógica. As empresas A, B, C e E confirmam o alinhamento.

As respostas estão de acordo com o esclarecimento de Lunkes, Feliu e Rosa (2011), quando disseram que os objetivos do orçamento devem estar alinhados com os definidos no planejamento em nível estratégico e tático.

Através do plano de negócio conseguimos manter o objetivo da empresa ou mudá-lo, mantê-lo alinhado com o orçamento torna os resultados mais verídicos. (Empresa B)

Quando questionados sobre as metas orçamentarias diárias, todas as empresas responderam que há metas a serem cumpridas.

As respostas condizem com o estudo de Priore et al. (2015), quando esclarecem que padronizar objetivos e metas de forma clara e transparente, facilita o gestor uma rápida análise das situações diárias e constantes:

É uma meta mensal que é dividida entre os dias do mês, para que o objetivo seja alcançado com maior efetividade e facilidade, não havendo constrição com os funcionários (Empresa B).

Quanto ao questionamento sobre o modelo orçamentário utilizado, somente a empresa $\mathrm{C}$ afirma utilizar o orçamento base zero obtendo processo que podem ser reduzidos ou eliminados. As empresas A, B, D e E utilizam o orçamento por atividades.

As respostas postas pelas empresas relatam desigualdades de modelo, o que não afeta o orçamento. Leite et al. (2008) complementa dizendo que as técnicas orçamentárias podem ser executadas em qualquer economia, para qualquer entidade, bastando apenas o conhecimento dos efeitos decorrentes da inflação, para que se construam sistemas de elaboração e acompanhamento de orçamentos, tanto em moeda corrente como em outra opção monetária. 
Quanto ao questionamento sobre a visualização do crescimento da organização no orçamento, todas as empresas declaram que o crescimento está claro na ferramenta. A declaração condiz com a afirmação de Priore et al. (2015), quando esclarecem que por meio do orçamento é possível visualizar e verificar o crescimento da organização:

Finalizado o período, realizamos uma reunião expondo os valores atingidos ,assim visualiza-se claramente o crescimento ou declínio da empresa. (Empresa C).

Quando questionados sobre a prioridade do planejamento e orçamento na tomada de decisão, todas as empresas afirmam que os dois são importantes para a escolha final.

Quando questionados sobre a importância do orçamento para as empresas familiares, todas as empresas declararam ser importante por diversas razões mas, principalmente, para a visão geral da situação da empresa.

Essas respostas estão de acordo com Kornacker et al. (2011), quando diz que o orçamento se tornou um pilar fundamental do planejamento e controle corporativo. $\mathrm{O}$ orçamento tem como função essencial incentivar, coordenar e documentar atividades de uma empresa:

Utilizamos os dois como base, porque eles mostram os objetivos e a situação atual da empresa, isso facilita muito a tomada de decisão. (Empresa B).

Através do orçamento conseguimos ver todas as áreas da empresa, onde e quando precisamos melhorar. (Empresa E).

Questionados se o orçamento na organização está mais ligado ao controle financeiro ou de estabelecimento de metas, a empresa $\mathrm{C}$ diz ser necessário para estabelecimento de metas. Já as empresas A, B, D e E afirmam estar ligado aos dois.

Por sua vez Zambon e Fassina (2014) declaram que os orçamentos podem ser efetuados como parte de um sistema de gestão tanto para um controle financeiro, como para as metas estabelecidas, além de permitir aos gestores rápidas respostas frente às situações imprevistas:

Precisamos decidir e visualizar a situação da empresa para a elaboração de metas e controlar e avaliar nosso financeiro (Empresa A). 
Questionados se fazer um orçamento afeta a competitividade no mercado, a empresa B nega dizendo que a competitividade está presente independente do orçamento. As empresas A, C, D e E concordam que sim.

As respostas coincidem com a afirmação de Silva, Rosa e Pires (2007), quando citam que a utilização de ferramentas sofisticadas para auxiliar na gestão das empresas, principalmente relacionadas aos custos de produção, tem criado um diferencial competitivo entre empresas concorrentes:

\begin{abstract}
Afeta a competitividade porque, com o orçamento temos uma visão mais ampla da situação da empresa, reduzindo assim os riscos de um mau investimento ou um investimento no momento errado e pode haver diferenças entre os orçamentos das empresas (Empresa C).
\end{abstract}

Quando questionados sobre os fatores influenciadores na elaboração do orçamento, as empresas A e B declaram em geral que fatores externos, entende-se por concorrência, e internos, por volume de vendas e demandas. Já as empresas C, D e E afirmam que como fator externo principal é a economia e fator interno o volume de vendas.

Almeida et al. (2009) afirma que se deve entender que os fatores externos, como tendências de mercados, condições econômicas e outras variáveis ambientais devem ser consideradas no processo de elaboração do orçamento:

Como fator externo posso citar a crise em que vivemos, porque a cada mudança, cada aumento de valor, aumento de imposto etc. devemos rever o orçamento e metas para que isso não agrida tanto nossa empresa (Empresa C).

Ao serem questionados sobre as dificuldades para a elaboração e controle do orçamento, as empresas declaram maior dificuldade sobre o controle do orçamento, pela falta de controle sobre os números, podendo estar vivenciando um imprevisto.

As respostas corroboram com o estudo de Lunkes, Feliu e Rosa (2011), quando afirmam que o controle orçamentário é o diagnóstico comparativo das medidas de desempenho projetadas com as executadas e quando necessário, a identificação dos desvios e suas justificativas e a aplicação das medidas de adequação: 
Se torna difícil a partir do momento em que os números se tornam irreais, por exemplo, tem um volume que deveria ser vendido, porém não atingimos este objetivo (Empresa C).

No momento que foram questionados se há ou houve previsão de prejuízos no orçamento, todas as empresas afirmam que já ocorreu, pelo fato de estarem sempre de olho no orçamento e ele proporcionar uma visão real e imediata da situação da empresa.

As respostas entram em harmonia com a posição Ward (2003), quando afirma que existem diversas ferramentas que previnem o declínio de uma entidade. Uma dessas ferramentas é o orçamento, fundamental para orientar a empresa e a família.

$\mathrm{O}$ orçamento nos proporciona uma visão ampla e atual, o que nos facilita ter o conhecimento de crescimento ou declínio (Empresa B).

Quando questionados sobre a interferência na utilização de ferramentas como orçamento pelo fato de ser uma empresa familiar, as empresas A, B e E declaram que o fato de ser familiar não interfere no orçamento. Já as empresas C e D dizem ter interferência em razão de haver diferenças entre ideias dos familiares.

As respostas estão ligadas à declaração de Alves e Buss (2009), ao citarem que como pontos de desvantagens das empresas familiares, viram-se aspectos ligados à sua estrutura organizacional informal, gestão desorganizada, confusão entre família e empresa e camuflagem de problemas.

Há divergências de ideias entre os familiares, o que dificulta alguns processos, algo que demoraria um ou dois dias leva semanas para ser concluído (Empresa C).

Ao serem questionados se a gestão da empresa permanece com os mesmos valores do fundador e se o mesmo é ou era preocupado com o orçamento, em geral, as empresas declaram que continuam com os mesmos processos e valores do fundador. Já sobre o fundador ser preocupado com o orçamento, as empresas A, B e D, afirmam que não havia a preocupação igual atualmente e as empresas $\mathrm{C}$ e $\mathrm{E}$ dizem que se preocupava com o orçamento.

Quanto a isso, Ward (2003) diz que se, por um lado, o orçamento ajuda o proprietário a concentrar sua atenção no negócio e, especificamente, na necessidade de 
fazer investimentos destinados a impor na empresa uma nova vontade e promover seu crescimento, por outro, garante que também todos os membros da família reconheçam e enfrentem as demandas da empresa. Além do mais, com o processo de preparação desse planejamento, coloca-se em evidência as necessidades da família, obrigatoriamente, abrem-se as portas para que sejam levadas em conta as metas familiares:

Pretendemos continuar seguindo com os valores e objetivos do fundador porque estes métodos sempre mantiveram nossa empresa unida de uma forma confortável de se trabalhar (Empresa B).

No momento em que foram questionados sobre o tempo que a empresa está no mercado e quantas gerações da família já passaram pela empresa, as empresas estão no mercado entre 40 e 50 anos e, em geral, estão na segunda geração.

As respostas corroboram com a citação de Sraer e Thesmar (2007), quando dizem que as empresas familiares superam em muito as corporações de grande porte:

\footnotetext{
A empresa está mais o menos no mercado a 50 anos, está na segunda geração agora com os filhos e os netos já estão trabalhando juntos também, sempre utilizando o orçamento, acredito que não porque como eu tinha falado os tempos eram outros, era avaliado de um outro jeito (Empresa A).
}

Questionados sobre o nível de competição da empresa por ser familiar e o modo que o orçamento é afetado, as empresas A, B e D afirmam ser um nível de competição normal e não afeta o orçamento. Já as empresas C e E afirmam se tornarem mais competitivas por diferentes razões.

As respostas podem ser complementadas pelo estudo de Allouche et al. (2008), quando afirmam que o nível de controle familiar influencia fortemente o desempenho, pelo menos, em termos de rentabilidade (embora os resultados não sejam tão claros para as estruturas financeiras). Além disso, o nível de controle da família tem consequências para o desempenho, requer confirmação em outros contextos nacionais e institucionais:

Torna-se um pouco mais competitiva, por ser familiar há muitas discordâncias entre os familiares e muitas vezes acaba afetando nosso orçamento (Empresa C). 
Questionados sobre os problemas familiares dentro da empresa, as empresas B, C e D afirmam que há ou houve momentos em que os familiares não souberam separar os problemas pessoais dos profissionais. Já as empresas A e E declaram ter grande controle sobre esse assunto.

As respostas estão de acordo com o estudo de Alves e Buss (2009), quando afirmam que a confusão entre família e empresa e a camuflagem de problemas é um ponto de desvantagem nas empresas familiares:

\footnotetext{
Já houve momentos em que ocorreu a interferência de problemas pessoais nos problemas profissionais, mas é importante ressaltar que hoje a empresa já está mais desenvolvida e aprendemos a lidar com a separação dos conflitos pessoais e profissionais para o bem da organização (Empresa B).
}

Questionados sobre os cargos ocupados pelos familiares, todas as empresas afirmaram que os mesmos são diretores. Em todas as empresas, o diretor financeiro é um familiar.

As respostas corroboram com Sraer e Thesmar (2007), que dizem que as empresas familiares superam em muito as corporações de grande porte. Esse resultado é válido para as empresas controladas pelo fundador, gerido profissionalmente empresas familiares, mas também, para empresas dirigidas por descendentes do fundador (SRAER;THESMAR, 2007).

A pessoa da família que está ligada ao orçamento é o diretor financeiro, filho do fundador (Empresa D).

Questionados sobre o envolvimento da família nos processos e os problemas ocasionados, todas as empresas, com exceção da empresa E, declaram já terem presenciado momentos de desavenças e não cumprimento de processos por conflitos familiares. Apenas a empresa $\mathrm{E}$ afirmou ser profissional quanto a isso.

As respostas estão em harmonia com o estudo de Massis e Kotlar (2014), quando afirmam que as empresas familiares são caracterizadas pela necessidade de equilibrar as identidades divergentes, interesses e prioridades dos membros da família e dos sistemas de negócios, dos quais os aspectos citados são particularmente difíceis para se capturar através de métodos quantitativos: 
Houve momentos em que os familiares entraram em conflito para tomar uma decisão, porém como eu já havia dito hoje a empresa já está mais desenvolvida (Empresa B).

Questionados se há dificuldade na tomada de decisão por ser familiar, as empresas $\mathrm{C}$ e D declaram passar por dificuldades para entrar em um acordo. As empresas A, B e E, afirmam que não há este obstáculo.

As respostas estão de acordo com Mucci, Frezzati e Dieng (2016), que afirmam que empresas familiares e de pequeno porte têm problemas com a gestão dos recursos, tanto por vincular o patrimônio da empresa com o familiar e vice-versa, quanto pela dinâmica organizacional sustentada pela informalidade e o desconhecimento do negócio.

Questionados se o fluxo financeiro é controlado por um membro da família, todas as empresas declaram que sim.

As respostas corroboram com o estudo de Lescura, Borges e Brito (2012), pois afirmam que as organizações que são dirigidas por indivíduos de uma família apresentam características que instigam os pesquisadores, pois tornam sua gestão diferenciada dos demais empreendimentos:

\section{É controlado pelo filho do fundador. (Empresa D).}

Questionados se a comunicação entre a família afeta a gestão dos recursos, as empresas A, B e E declaram não afetar a gestão. Já as empresas C e D afirmam que ocorre ou já ocorreram casos em que a gestão foi interferida por esse motivo.

As respostas estão em harmonia com o estudo de Songini, Gnan e Malmi (2013), que afirmam que a empresa familiar não representa um grupo homogêneo, mas há diversos fatores emergenciais que a diferencia, eles são: o grau de envolvimento da família, a presença de membros que não são da família, tanto na propriedade, bem como na governança e na gestão, e isso também caracteriza a empresa nas questões de contabilidade (SONGINI; GNAN; MALMI, 2013). 


\section{CONSIDERAÇÕES FINAISS}

O orçamento, assim como o planejamento, são ferramentas de gestão que permitem uma visão futura da empresa, sendo, portanto, essenciais para a tomada de decisão, evitando o mau uso dos recursos, resultando na otimização dos resultados. (SOUZA; CANTON; JOHANN, 2014).

Esta pesquisa teve como objetivo compreender como é o processo de construção, execução e controle do orçamento em empresas familiares. Após a coleta dos dados, notase no geral, que a dificuldade da gestão orçamentaria nas empresas familiares e são os possíveis conflitos pessoais e profissionais entre os membros da família, colocando à frente objetivos que muitas vezes não atendem as necessidades das empresas. $\mathrm{O}$ fato de a empresa ser familiar pode deixar problemas ocultos gerando morosidade.

Além disso, quando o profissionalismo dos familiares é bem estruturado, a empresa ganha um grande diferencial, além de gerar harmonia entre funcionários e diretores, o que aumenta a competitividade e rapidez.

O fato de os membros da família interferirem ou se envolverem diretamente na construção, execução e controle do orçamento, pode atrapalhar o processo por haver divergências de opiniões, o que dificulta alguns procedimentos que poderiam ser resolvidos em dias, mas levam semanas para serem concluídos.

De acordo com as entrevistas, em empresas familiares os problemas, muitas vezes, são omitidos afetando principalmente a tomada de decisão. Essa situação, de acordo com as entrevistas, também afeta o processo orçamentário gerando morosidade e inconsistências.

Esta pesquisa pode auxiliar as empresas familiares a controlar, planejar e executar de forma mais eficiente seus orçamentos. Além disso, a gestão orçamentária é considerada um instrumento à disposição das organizações para garantir eficiência do controle gerencial, mas para que essa eficiência decorra, o orçamento deve passar por diversos processos até de fato estar perfeito para sua empresa.

Como principais limitações, enumera-se o fato de que a amostra é pequena e pode não representar a realidade de todas as empresas familiares. Como possíveis trabalhos futuros, podem-se sugerir uma pesquisa que busque compreender a efetividade na prática 
dos orçamentos nas empresas. Sugere-se, também, analisar diferentes setores em empresas familiares buscando compreender como essa variável de controle "setor" afeta o orçamento.

\section{REFERENCIAS}

ALLOUCHE, J., et al., The Impact of Family Control on the Performace and Financial Characteristics of Family Versus Nonfamily Businesses in Japan: A Matched-Pair Investigation, Journal Family Firm Institute, Inc., Massachusetts, p. 315 - 329, dezembro/ 2008.

ALMEIDA, L. B., et al., Apoio à Formulação de Estratégia, de Controle e de interatividade: Um Estudo Exploratório nas Cooperativas Agropecuárias da Região Sul do Brasil, Revista Contabilidade Vista \& Revista, Minas Gerais, v. 20, n. 3, p. $65-99,2009$.

ALVES, T. L. P. e BUSS, R. N., O Administrador e a Gestão de Empresas Familiares, Revista São Luis Orione, Tocantins, v. 1, n. 3, p. 81 - 112, 2009.

ANDRADE, L.P; CAPELLE, M.C.A; CAMPOS, R. C. e e BRITO, M.J.. Meu pai ainda está aqui, nas pessoas: sentidos subjetivos nas relações de trabalho em uma empresa familiar. Revista de Empreendedorismo e Gestão de Pequenas Empresas, 7(2),145$169,2018$.

BECK, F.; CUNHA, P. R. e FRANZ, L., Honorários de auditoria: uma análise das empresas familiares e não familiares listadas na BM\&F Bovespa, Revista Brasileira de Gestão de Negócios, São Paulo, v. 17, n. 54, p. 720 - 735, 2015.

CAVALCANTI, C. X., Implantação do Orçamento como Ferramenta de Controle Gerencial: Um Estudo de Caso em uma Empresa de Médio Porte do Ramo de Rochas Ornamentais, Revista ADM.MADE, Rio de Janeiro, v. 17, n. 2, p. 1 - 12, 2013.

CHAGAS, M. J. R. e ARAUJO, A. O., Orçamento Empresarial como Ferramenta de Auxílio à Gestão: Um Estudo Empírico nas Indústrias de Calçados da Cidade de Campina Grande-PB1, REUNIR - Revista de Administração, Contabilidade e Sustentabilidade, Paraíba, v. 3, n. 3, p. 1 - 21, 2013.

CODESSO, M. M., et al., Práticas Orçamentárias Aplicadas em Empresas Hoteleiras no Brasil: um estudo na cidade de Balneário Camboriú, Revista Turismo Visão e Ação - Eletrônica, Santa Catarina, v. 15, n. 2, p. 279 - 294, 2013.

COSTA, A. M., MORITZ, G. O. e MACHADO, F. M. V., Contribuições do Orçamento Base Zero (OBZ) no Planejamento e Controle de Resultados em 
Organizações Empresariais, Revista Contemporânea de Contabilidade, Santa Catarina, v. 1, n. 8, p. 85 - 98, 2007.

COSTA, L. S. P., et al., De Pai para Filho: A Sucessão em Pequenas e Médias Empresas Familiares, Contabilidade, Gestão e Governança, Brasília, v. 18, n. 1, p. 61 $-82,2015$.

CRAIG, J. e MOORES, K., Strategically aligning family and business systems using the Balanced Scorecard, Journal of Family Business Strategy, Australia, p. 78 - 87, $\mathrm{jan} / 2010$.

DEBOLETO, G. A. G., et al., Análise do uso do Orçamento Empresarial em uma Empresa de Pequeno Porte: Um Estudo de Caso num Comércio de Iluminação, Comunicação \& Mercado, Mato Grosso do Sul, vol. 1, n. 4, p. 98 - 114, 2013.

FERREIRA, F. B. e DIEHL, C. A., Orçamento Empresarial e suas Relações com o Planejamento Estratégico, Pensar Contábil, Rio de Janeiro, v. 14, n. 54, p. 48 - 57, 2012.

FREZATTI, F., Beyond Budgeting: Inovação ou Resgate de Antigos Conceitos do Orçamento Empresarial?, ERA - Revista de Administração de Empresas, São Paulo, v. 45, n. 2, p. 23 - 33, 2005.

FREZZATI, F.; DIOGENES, S.B; MUCCI, D. M e Beck, F., Estágio do ciclo de vida e perfil de empresas familiares brasileiras. RAE- Revista de Administração de Empresa, 2017, Vol.57(6), p.601(19).

GOMES, G., LAVARDA, C. E. F. e TORRENS, E. W., Revisão da Literatura sobre Orçamento em Cinco Periódicos Internacionais nos anos de 2000 até 2009, REGE, São Paulo, v. 19, n. 1, p. 107 - 123, 2012.

KORNACKER, J., SCHENTLER, P., WILLIAMS, H. J. e MOTWANI, J., Critical success factors for budgeting systems in the German context: an empirical analysis, Int. J. Business Excellence, Alemanha, v. 4, n. 6, p. 621 - 644, 2011.

LAVARDA, C. E. F. e PEREIRA, A. M., Planejamento e Controle orçamentário empresarial como Ferramenta de Apoio à Tomada de Decisão, ABCustos, São

Leopoldo: Associação Brasileira de Custos, Rio Grande do Sul, v. 6, n. 1, p. 39 - 56, 2011.

LEITE, R. M., et al., Orçamento Empresarial: Levantamento da Produção Científica no Período de 1995 a 2006, Revista Contabilidade \& Finanças, São Paulo, v. 19, n. 47, p. $56-72,2008$.

LESCURA, C.; BORGES, F. A. e BRITO, M. J., Relações de Parentesco em Empresas Familiares: Uma Abordagem Sócio antropológica, Revista Eletrônica de Gestão

Organizacional, Recife, v. 10, n. 3, p. 595 - 622, 2012. 
LIMA FILHO, R. N. e BRUNI, A. L., Quanto mais faço, mais erro? Uma Análise sobre a Presença de Vieses Cognitivos em Julgamentos sobre Orçamento, BASE - Revista de Administração e Contabilidade da Unisinos, Bahia, v. 10, n. 3, p. 225 - 239, 2013.

LOPES, A. L. e BLASCHEK, J. R. S., Minimizando as Deficiências do Planejamento Operacional com o Uso do Orçamento Baseado em Atividades, Revista de Contabilidade do Mestrado em Ciências Contábeis da UERJ, Rio de Janeiro, v. 12, n. 2, p. 1 - 16, 2007.

LUNKES, R. J., FELIU, V. M. R. e ROSA, F. S., Pesquisa sobre Orçamento na Espanha: Um Estudo Bibliometrico das Publicações em Contabilidade, Revista Universo Contábil, Santa Catarina, v. 7, n. 3, p. 112 - 132, 2011.

MARQUES, J. C., et al., Plano de Sucessão em Empresas Familiares no Município de Primavera do Leste, Revista Eletrônica Gestão e Serviços, Mato Grosso, v. 6, n. 2, p. 1384 - 1401, 2015.

MARTH, A. e FEIL, A. A., Implantação do Orçamento Base Zero na Gestão de uma Empresa de Radiodifusão, Revista Eletrônica de Administração e Turismo, Rio Grande do Sul, v. 5, n. 3, p. 489 - 507, 2014.

MASSIS, A. e KOTLAR, J., The case study method in family business research: Guidelines for qualitative scholarship, Journal of Family Business Strategy, Australia, p. 15 - 29, maio/ 2014.

MAVÁREZ, A.C; QUIROZ, C.A.M; CHANCAY, T.S.A e LOPEZ, V. E.R., Sistema familiar y continuidad de las empresas familiares. Revista de Ciencias Sociales (Ve), XXV(4), 2019.

MONTEIRO, J. M. e BARBOSA, J. D., Controladoria Empresarial: Gestão Econômica para as Micro e Pequenas Empresas, RMPE - Revista da Micro e Pequena Empresa, São Paulo, v. 5, n. 2, p. 38 - 59, 2011.

MUCCI, Daniel Magalhães; FREZATTI, Fabio; DIENG, Mamadou. As Múltiplas Funções do Orçamento Empresarial. Rev. adm. contemp., Curitiba , v. 20, n. 3, p. 283-304, June 2016 .

NASCIMENTO, G. H. F. e TEIXEIRA, M. S. F. S., O Orçamento Empresarial como Ferramenta de Gestão e Instrumento de Controle na Empresa ABCIND: Um Estudo de Caso, CONCISA - Revista Multidisciplinar da Área de Ciências Sociais Aplicadas, Minas Gerais, n. 2, p. 386 - 399, 2015.

PIOVESAN, A. e TEMPORINI, E. R., Pesquisa exploratória: procedimento metodológico para o estudo de fatores humanos no campo da saúde pública, Revista Saúde Pública, São Paulo, v. 29, n. 4, p. 318 - 325, 1995. 
PIRES, J. S. D. B. e MOTTA, W. F., A Evolução Histórica do Orçamento Público e sua Importância para a Sociedade, Enfoque - Reflexão Contábil, Paraná, v. 25, n. 2, p. $16-25,2006$.

PONTES, G. A., Orçamento Empresarial em Pequenas Empresas: Uma Análise para o Planejamento e Controle de Resultados, GETEC, Minas Gerais, v. 2, n. 1, p. 27 - 45, 2013.

PORFÍRIO, J.A; FELÍCIO, J.A. e CARRILHO, T. Family business succession: Analysis of the drivers of success based on entrepreneurship theory. Journal of Business Research. Volume 115, Pages 250-257, July 2020,

PRIORE, E. R., et al., A Importância do Planejamento e Orçamento: Um Estudo de Caso Sobre o uso da Ferramenta de Orçamento em um Condomínio, ENIAC Pesquisa, São Paulo, v. 4, n. 1, p. 67 - 80, 2015.

QUINTANA, A. C., PERAZO, A. N. C. e FERNANDES, V. L. P., A Grade Curricular dos Cursos de Ciências Contábeis e os Resultados Institucionais no ENADE: Um Estudo nas Disciplinas da Área da Contabilidade Financeira e de Orçamento, Revista GUAL, Santa Catarina, v. 6, n. 3, p. 127 - 145, 2013.

RUIZ, C.D; GUSMÁN, R. C.; VALENCIA, E. J. P. Funcionalidad familiar como estrategia para la generación del emprendimiento social en México. Revista Venezoelana de Gerência, 25(89),79-91, 2020.

SILVA A. T., ROSA, P. M. e PIRES, J. S. D. B., Uma Aplicação Prática de Orçamento Baseado em Atividades, UnB Contábil, Brasília, vol. 10, n. 2, p. 147 $171,2007$.

SONGINI, L., GNAN, L. e MALMI, T., The role and impact of accounting in family business, Journal of Family Business Strategy, Australia, p. 71 - 83, abril/ 2013.

SOUZA, D.; CANTON, F. M. D. e JOHANN, G. B., O Papel do Orçamento no Plano Estratégico de um Supermercado, Revista de Administração, Rio Grande do Sul, v. 12, n. 21, p. $111-125,2014$.

SOUZA, P. e LUNKES, R. J., Praticas de orçamento: um estudo em empresas hoteleiras do Brasil, RETUR - Revista Brasileira de Pesquisa em Turismo, São Paulo, v. 9, n. 3, p. 380 - 399, 2015.

SRAER, D. e THESMAR, D., Performance and behavior of family firms: evidence from the French stock market, Journal of the European Economic Association, Europa, p. 709 - 751, junho/ 2007. 
TAPPEINER, F., et al., Demand for private equity minority investments: A study of large family firms, Journal of Family Business Strategy, Australia, p. 38 - 51, março/ 2012.

VANZELLA, C. e LUNKES, R. J., Orçamento Baseado em Atividades: um estudo de caso em empresa distribuidora de energia elétrica, Contabilidade Vista \& Revista, Minas Gerais, v. 17, n. 1, p. 113 - 132, 2006.

VERGARA, S. C., Método de Pesquisa de Administração, São Paulo, 2012, Ed. Atlas.

WARD, P. J. L., Planejar Para Prosseguir, Hsm Management, Paraná, v. 6, n. 41, p.83, 2003.

WEROLIN, A. E., A Elaboração de um Orçamento Variável, National Associetion of Accountants, Nova Iorque, v. 46, n. 5, p. 128 - 144, 1964.

WIENHAGE, P. e LAVARDA, C. E. F., Avaliação do sistema orçamentário como instrumento de gestão em empresas em processo de descontinuidade, RIC Revista de Informação Contábil, Pernambuco, v. 6, n. 1, p. 23 - 38, 2012.

ZAMBON, E.P. e FASSINA, P. H., Orçamento Empresarial: Uma Análise em Estudos Internacionais, Revista Científica Fazer, v. 1, n. 3, p. 42 - 56, 201

ZONATTO, V. C. S; WEBER, A. e NASCIMENTO, Juliana Constâncio, Efeitos da Participação Orçamentária na Assimetria Informacional, Estresse Ocupacional e Desempenho Gerencial, RAC - Revista de Administração Contemporânea, 23(1),6791, 2019. 